\title{
Predictive factors of the duration of sick leave due to mental disorders
}

\author{
Sawako Sakakibara ${ }^{1}$, Mitsuhiro Sado ${ }^{2,3^{*}}$ (D) Akira Ninomiya ${ }^{2,3}$, Mayuko Arai ${ }^{2,3}$, Satoko Takahashi ${ }^{2,3}$, \\ Chika Ishihara ${ }^{2,3}$, Yuki Miura ${ }^{2,3}$, Hajime Tabuchi ${ }^{2,3}$, Joichiro Shirahase ${ }^{2,3}$ and Masaru Mimura ${ }^{2,3}$
}

\begin{abstract}
Background: This study aimed to examine potential predictors of duration of sick leave due to mental disorders in Japan.

Methods: A total of 207 employees at a manufacturing company in Japan with a past history of sick leave due to mental disorders participated in this study. Mental disorders were defined as those listed in the Diagnostic and Statistical Manual of Mental Disorders, Fourth Edition (DSM-IV). All of the participants used the mental health program that the company provided. The predictive power of the variables was tested using a Cox proportional hazard analysis. The hazard ratios in the final model were used to identify the predictor variables of the duration of sick leave. We included socio-demographic (age, sex, tenure), clinical (diagnosis and number of previous sick leave), and work-related factors (employment rank) as possible predictors. Data on these variables were obtained through the psychiatrists and psychologists in the company's mental health program.
\end{abstract}

Results: The results of the univariate analyses showed that the number of previous sick leave episodes, diagnosis and employee rank were significant predictors of the duration of sick leave due to mental disorders. A multivariate analysis indicated that age, number of previous sick leave and employee rank were statistically significant predictors of return to work.

Conclusions: Diagnosis, number of previous sick leave episodes, and employee rank are predictors of the duration of sick leave due to mental disorders. This study's findings have implications in the development of effective interventions to prevent protracted sick leave.

Keywords: Return to work, Mental disorders, Sick leave, Employee, Occupational mental health

\section{Background}

Mental disorders are highly prevalent in the general population, and cause considerable burden to society [1-3]. Previous studies in Japan indicated that the total costs of mental disorders are enormous. Total cost of schizophrenia, depression, and anxiety disorder in Japan in 2008 was Japanese Yen (JPY) 2.77 trillion (United States Dollars (USD) 23.8 billion), JPY 3.09 trillion (USD 26.5 billion), and JPY 2.39 trillion (USD 20.5 billion), respectively $[4,5]$. When it comes to the workplace, it is well known

\footnotetext{
${ }^{*}$ Correspondence: mitsusado@keio.jp

2 Department of Neuropsychiatry, Keio University School of Medicine,

Shinanomachi 35, Shinjuku-ku, Tokyo 160-8582, Japan

Full list of author information is available at the end of the article
}

that mental disorders contribute to sick leave of employees in Western countries [1, 6-8] and also in Japan [9]. Mental disorder is one of the main causes of absenteeism in employees $[10,11]$. Despite the enormous negative effects of sick leave due to mental health problems, our knowledge about prognostic factors for the duration of sick leave is still very limited $[12,13]$.

The duration of sick leave due to mental disorders, such as adjustment disorder, depression, anxiety disorder, and schizophrenia, is longer than that due to physical disorders [14]. The costs of sick leave caused by mental disorders are extremely high not only for the individual but also for their workplace and society $[3,15,16]$. Therefore, delays in returning to work result in high compensation costs. Nevertheless, studies on return-to-work 
rehabilitation programs for workers with mental disorders are very limited [12, 13, 17]. A better understanding of the prognostic factors for longer sick leave would be helpful to develop effective prevention and intervention strategies for reducing the costs and personal distress associated with longer-term sick leave.

A systematic review article by Cornelius et al. [12] revealed that older age ( $>50$ years) was strongly associated with longer duration of sick leave until returning to work. However, it is not clear whether this finding could be applicable to non-Western countries like Japan, where the healthcare system and employment contracts regarding sick leave differ from those in Western countries. For example, it is fairly common for the employees of Japanese large companies to have the right to take sick leave over 3 years. To the authors' knowledge, there have been few studies that have investigated this issue in Japan. The only study in Japan relevant to this context is the one conducted by Sado et al. [18]. However, the focus of the Sado et al's study lies on the risk factors for 'repeated sick leave' after return to work. With respect to the risk factors for 'duration of sick leave' in this study, there have been no studies to the authors' knowledge. Therefore, we decided to evaluate the variables, relevant to socio-demographic, clinical, and work related, that predict duration of sick leave due to mental disorders in Japan.

\section{Objective}

The objective of this study is to examine the variables, relevant to socio-demographic, clinical, and work related, that predict duration of sick leave due to mental disorders in Japan.

\section{Methods}

The method adopted for this study follows that described in the previous study by Sado et al. [18], the same data set was utilized. However, the variables included in the analysis of this study differs from the earlier study. The dependent variables in Sado et al. [18]. was the number of survival days (the duration between the return to work and the repeated sick leave). On the other hand, the dependent variable of this study is the number of sick leave days (the duration between starting sick leave and returning to work).

\section{Design}

This was a retrospective cohort study. This study was approved by the Clinical Research Ethics Committee at Keio University School of Medicine (reference: 2013-485).

\section{Participants}

This study was carried out in a company with approximately 10,000 employees in the Tokyo metropolitan area. The company is one of the most well-known manufacturing companies in Japan, mainly developing home electrical products.

Data was derived from 207 workers of the company. Participants started their sickness absence from work between April 1, 2009 and March 31, 2012. All employees were included in this study, who took sick leave longer than successive 20 days due to their mental disorders during that period. The reason for the cutoff point of 20 days was that in the company's regulations, employees who took over successive 20 days sick leave must have undergone an assessment by an occupational psychiatrist to determine whether they were mentally fit to return to work in the rehabilitation program. The program also includes reinstatement support by occupational psychiatrists and psychologists. All participants in this study utilized the program.

Clinical diagnoses in this study were made by a senior occupational psychiatrist according to the criteria of Diagnostic and Statistical Manual of Mental Disorders, fourth edition (DSM-IV). He judged on the basis of the information from psychiatrists and psychologists in the program who had sessions with the participants, their coworkers and personnel in the company's human resource division. The diagnosis affecting the most recent sick leave was coded as primary diagnosis. When participants took sick leave due to both physical and mental disorders, they were included in the analyses only if the main reason for sick leave was judged to be mental disorders. In the case of multiple psychiatric diagnoses, the disorder playing the strongest role in the sickness absence was coded as the diagnosis and used for analyses in this study.

\section{The process of return to work after sick leave in the company}

Soon after a worker submits a medical certificate for returning to work to the human resources division, they are referred to the occupational mental health support team in the company. They then participate in the rehabilitation program provided by the team, using cognitive behavioral therapy components such as behavioral activation and activity scheduling. In the program, after four sessions of the intervention, workers are evaluated by the team psychiatrist in terms of their fitness to work. After this process is successful, workers return to work with some restrictions on engagement, such as no overtime duties for a period of time. The restrictions on engagement are expected to be gradually reduced over 6 months until they are lifted completely. 


\section{Variables in the study Dependent variable}

The dependent variable was the number of sick days off due to mental disorders. We counted the duration between starting to take sick leave due to mental disorders and return-to-work or March 31, 2012 if they didn't return to work at that time.

\section{Explanatory variables}

Although various factors are likely to predict return to work $[1,19]$, our choice of explanatory variables in this study was based on the difficulty in obtaining information of various types and data on many variables through time-consuming processes such as structured interviews with employees returning to work during their usual rehabilitation program activities. Therefore, we judged it more appropriate in these circumstances to use readily accessible variables that are likely to prolong absence from work. The following were chosen as explanatory variables in this study.

\section{Socio-demographic factors:}

Age of participant when sick leave started (20-29 years, 30-39 years, 40-49 years, and 50 years and older), sex, age at start of employment (under 25, 25-29, 30 or over) and job tenure (under $5,5-9,10-19$, over 19 years).

\section{Clinical factors:}

Diagnosis (major depressive disorder, adjustment disorder, bipolar disorder, anxiety disorder, schizophrenia, and other disorders), and number of previous sick leave (none, one, and two and more).

\section{Work-related factors:}

Employee rank (assistant staff, middle staff, senior staff, and managers); employee rank in the company is strongly related to the job role; typical job roles for each employee rank are described below.

Assistant staff: expected to support other staff in working efficiently; typically, assistant staff have graduated from high school or junior college.

Middle staff: expected to conduct tasks assigned by senior staff and to usually follow instructions from their team leaders to conduct their work; typically, each worker stays in this position for 5-10 years after graduating from university or graduate school.

Senior staff: expected to work as leaders of their team, which typically consists of middle and assistant staff; their mission is to manage their team to carry out the tasks assigned by their manager; they are also expected to communicate efficiently with other senior staff working as team leaders and managers in order to conduct their projects successfully; typically, senior staff members are in their mid-30 s to $40 \mathrm{~s}$.

Managers: expected to operate their projects by managing several teams; their main roles are to provide team leaders with objectives and oversee the development of projects through discussions with team leaders; typically, they are over 40 years of age.

\section{Analysis}

Firstly, we examined the characteristics of the participants. Subsequently, univariate analysis was conducted. The dependent variable (number of sick days off work due to mental disorders) was censored when participants' sick leave continued until March 31, 2012, or if they retired or transferred out of the Tokyo metropolitan branch by this date. Each explanatory variable was assessed using the log-rank test. Next, Cox proportional hazard analysis was conducted to identify relevant predictors of the duration of sick leave using a stepwise forward selection method. All analyses were conducted with SPSS for Windows, version 19, the license for which was provided by Keio University School of Medicine.

In this study, we utilized secondary data that had been already obtained during the usual process of return to work in the company. As mentioned above, this maximizes practical value; that is, the potential predictors are easily available to occupational psychiatrists in this and other companies in Japan. In addition, we used only anonymous data. We conducted this study with opt out consent method.

\section{Results}

\section{Characteristics of the participants}

\section{Socio-demographic factors}

The mean age of start of sick leave in this study was $38.3(S D=7.39)$ years. Mean age at start of employment and job tenure were $25.6(S D=3.81)$ and $14.9(S D=8.13)$ years, respectively.

\section{Clinical factors}

While $68.1 \%(n=141)$ of participants had never experienced an episode of sick leave before, $17.9 \%(n=37)$ had experienced one previous sick leave episode due to mental disorders, and $14.0 \%(n=29)$ had experienced two or more.

A total of $50.2 \%(n=104)$ of participants were diagnosed with major depressive disorder, $27.5 \%(n=57)$ with adjustment disorder, $6.3 \%(n=13)$ with bipolar disorder, 
$3.4 \%(n=7)$ with anxiety disorder, and $3.4 \%(n=7)$ with schizophrenia. Other diagnoses $(9.2 \%, n=19)$ included personality disorders, substance related disorders, pervasive development disorders, disruptive behavior disorder, and unspecific mental disorders.

\section{Work-related factors}

While $17.4 \%(n=36)$ of participants were managers, 48.8\% ( $n=101), 30.0 \%(n=62)$, and $3.9 \%(n=8)$ were senior staff, middle staff, and assistant staff, respectively.

\section{Duration of sick leave}

The mean number of sick days off work due to mental disorders was $235.8(S D=228.4)$ days.

The details of the participant characteristics are shown in Table 1.

\section{Univariate analysis}

Univariate analysis was conducted. Each explanatory variable was assessed using the log-rank test. The number of days of previous sick leave, diagnosis, and employee rank were significant. With respect to diagnosis, the workers with schizophrenia took significantly longer sick leave compared to those with adjustment disorders. The details of this analysis are shown in Table 2.

\section{Multivariate analysis}

We investigated multicollinearity among independent variables using Spearman's rank correlation coefficient. The results showed a strong relationship between age and tenure $(r=0.81)$. Therefore, we conducted a Cox proportional hazard analysis for evaluating predictors of the duration of sick leave excluding tenure as a predictor variable. Table 3 shows the variables retained in the final Cox's regression model with forced entry (sex and age) and stepwise forced selection procedure (all variables except sex and age). Three statistically significant predictors of the duration of sick leave were yielded by this process: age, number of previous sick leave, and employee rank, as discussed in more detail below.

In regard to age, the hazard ratios $(95 \% \mathrm{CI})$ of $30-39$ years, $40-49$ years, and 50 years and older were 0.35 (0.19-0.64), $0.30(0.15-0.62)$, and $0.75(0.28-2.00)$, respectively, when $20-29$ years was set to be the reference category.

With respect to the number of days of previous sick leave, when no history of previous sick leave was used as the reference, the hazard ratios of one previous episode, and two or more previous episodes were 0.79 (0.48-1.29) and $0.49(0.28-0.86)$, respectively.

With respect to employee rank, the hazard ratios of senior staff, normal staff, and assistant staff were 1.55 (0.90-2.66), 0.65 (0.32-1.30), and 0.12 (0.03-0.56),
Table 1 Characteristics of the participants

\begin{tabular}{|c|c|c|c|c|}
\hline Variables & $\mathbf{n}$ & $\%$ & Mean & SD \\
\hline \multicolumn{5}{|l|}{ Socio-demographic } \\
\hline Age at start of sick leave (years) & & & 38.3 & 7.39 \\
\hline $20-29$ & 26 & 12.6 & & \\
\hline $30-39$ & 96 & 46.4 & & \\
\hline $40-49$ & 72 & 34.8 & & \\
\hline$\geqq 50$ & 13 & 6.3 & & \\
\hline \multicolumn{5}{|l|}{ Sex } \\
\hline Male & 168 & 81.2 & & \\
\hline Female & 39 & 18.8 & & \\
\hline Age at employment (years) & & & 25.6 & 3.81 \\
\hline$<25$ & 93 & 44.9 & & \\
\hline $25-29$ & 86 & 41.5 & & \\
\hline$\geqq 30$ & 28 & 13.5 & & \\
\hline Tenure (years) & & & 14.9 & 8.13 \\
\hline$<5$ & 22 & 10.6 & & \\
\hline $5-9$ & 32 & 15.5 & & \\
\hline $10-19$ & 87 & 42.0 & & \\
\hline$\geqq 20$ & 66 & 31.9 & & \\
\hline \multicolumn{5}{|l|}{ Clinical } \\
\hline \multicolumn{5}{|l|}{ Number of previous sick leave } \\
\hline 0 & 141 & 68.1 & & \\
\hline 1 & 37 & 17.9 & & \\
\hline $2 \leqq$ & 29 & 14.0 & & \\
\hline \multicolumn{5}{|l|}{ Diagnosis } \\
\hline Major depressive disorder & 104 & 50.2 & & \\
\hline Adjustment disorder & 57 & 27.5 & & \\
\hline Bipolar disorder & 13 & 6.3 & & \\
\hline Anxiety disorder & 7 & 3.4 & & \\
\hline Schizophrenia & 7 & 3.4 & & \\
\hline Others & 19 & 9.2 & & \\
\hline Duration of sickness absence (days) & & & 235.8 & 228.4 \\
\hline \multicolumn{5}{|l|}{ Work related } \\
\hline \multicolumn{5}{|l|}{ Employee rank } \\
\hline Manager & 36 & 17.4 & & \\
\hline Senior staff & 101 & 48.8 & & \\
\hline Normal staff & 62 & 30.0 & & \\
\hline Assistant staff & 8 & 3.9 & & \\
\hline
\end{tabular}

$S D$ standard deviation

respectively, when manager was set to be the reference category. Further details are shown in Table 3.

\section{Discussion}

Considering that a large portion of the productivity loss caused by mental disorders occurs at the workplace, efforts to minimize the duration of sick leave are critical. As far as we know, this is the first study examining the predictors of duration of sick leave due to mental disorders among employees in Japan. Age, number of 
Table 2 Predictors for duration of sick leave (univariate analysis)

\begin{tabular}{|c|c|c|c|c|c|c|c|}
\hline \multirow[t]{2}{*}{ Variables } & \multirow{2}{*}{$\begin{array}{l}\text { Estimated mean days } \\
\text { of sick leave }\end{array}$} & \multirow[t]{2}{*}{ SE } & \multicolumn{2}{|l|}{$95 \% \mathrm{Cl}$} & \multirow[t]{2}{*}{$x^{2}$} & \multirow{2}{*}{$\begin{array}{l}\text { Degree } \\
\text { of freedom }\end{array}$} & \multirow[t]{2}{*}{$p$} \\
\hline & & & Lower & Upper & & & \\
\hline \multicolumn{8}{|l|}{ Socio-demographic } \\
\hline \multicolumn{8}{|l|}{ Age at start of sick leave } \\
\hline $20-29$ & 215.9 & 40.5 & 136.5 & 295.3 & 4.07 & 3 & 0.254 \\
\hline $30-39$ & 346.1 & 35.7 & 276.0 & 416.1 & & & \\
\hline $40-49$ & 331.8 & 41.8 & 250.0 & 413.7 & & & \\
\hline$\geqq 50$ & 218.1 & 73.6 & 73.8 & 362.5 & & & \\
\hline \multicolumn{8}{|l|}{ Sex } \\
\hline Male & 318.6 & 26.9 & 265.9 & 371.3 & 0.33 & 1 & 0.564 \\
\hline Female & 327.9 & 50.5 & 228.8 & 427.0 & & & \\
\hline \multicolumn{8}{|c|}{ Age at start of employment (years) } \\
\hline$<25$ & 331.8 & 36.4 & 260.5 & 403.0 & 1.16 & 2 & 0.561 \\
\hline $25-29$ & 339.0 & 40.3 & 259.9 & 418.0 & & & \\
\hline$\geqq 30$ & 235.1 & 44.3 & 148.2 & 322.0 & & & \\
\hline \multicolumn{8}{|l|}{ Tenure (years) } \\
\hline$<5$ & 240.6 & 50.8 & 141.0 & 340.2 & 4.12 & 3 & 0.249 \\
\hline $5-9$ & 289.6 & 61.9 & 168.2 & 410.9 & & & \\
\hline $10-19$ & 322.4 & 35.2 & 253.4 & 391.5 & & & \\
\hline$\geqq 20$ & 371.6 & 46.2 & 281.1 & 462.1 & & & \\
\hline \multicolumn{8}{|l|}{ Clinical } \\
\hline \multicolumn{8}{|l|}{ Number of previous sick leave } \\
\hline 0 & 282.9 & 26.4 & 231.3 & 334.6 & 8.36 & 2 & 0.015 \\
\hline $1-2$ & 367.5 & 62.4 & 245.1 & 489.8 & & & \\
\hline$\geqq 3$ & 444.8 & 72.7 & 302.4 & 587.3 & & & \\
\hline \multicolumn{8}{|l|}{ Diagnosis } \\
\hline Major depressive disorder & 330.2 & 33.3 & 265.0 & 395.4 & 13.96 & 5 & 0.016 \\
\hline Adjustment disorder & 237.8 & 40.9 & 157.7 & 317.9 & & & \\
\hline Bipolar disorder & 389.8 & 171.3 & 54.0 & 725.5 & & & \\
\hline Anxiety disorder & 506.2 & 145.1 & 221.8 & 790.6 & & & \\
\hline Schizophrenia & 586.9 & 130.0 & 332.0 & 841.7 & & & \\
\hline Others & 328.2 & 69.8 & 191.4 & 465.0 & & & \\
\hline \multicolumn{8}{|l|}{ Work related } \\
\hline \multicolumn{8}{|l|}{ Employee rank } \\
\hline Manager & 304.7 & 47.4 & 211.8 & 397.7 & 10.80 & 3 & 0.013 \\
\hline Senior staff & 260.8 & 30.8 & 200.4 & 321.1 & & & \\
\hline Normal staff & 378.0 & 45.6 & 288.7 & 467.4 & & & \\
\hline Assistant staff & 663.3 & 123.4 & 421.4 & 905.1 & & & \\
\hline
\end{tabular}

previous sick leave, and employee rank were found to be related to duration of sick leave.

\section{Socio-demographic factors}

The duration of sick leave of participants in their $30 \mathrm{~s}$ and $40 \mathrm{~s}$ was significantly longer than that of those in their $20 \mathrm{~s}$. A possible reason for this is the longer working hours of those in their $30 \mathrm{~s}$ and $40 \mathrm{~s}$ compared to other age groups in Japan [20]. Longer working hours may negatively affect the mental health condition of workers in their $30 \mathrm{~s}$ and $40 \mathrm{~s}$, which could make their sick leave longer. A review of the prognostic factors of sick leave in Western countries showed that the duration of sick leave of workers in their $50 \mathrm{~s}$ was longer than in other age groups [12]. However, this study showed that the duration of sick leave in the $50 \mathrm{~s}$ age group was not significantly longer than in other age groups in Japan. One reason for this could be that the number of participants in their $50 \mathrm{~s}$ in this study was too small to detect statistical significance. An additional possibility could 
Table 3 Predictors for duration of sick leave (multivariate analysis)

\begin{tabular}{|c|c|c|c|c|c|c|c|c|}
\hline \multirow[t]{2}{*}{ Predictor } & \multirow[t]{2}{*}{$B$} & \multirow[t]{2}{*}{$S E$} & \multirow[t]{2}{*}{ Wald } & \multirow{2}{*}{$\begin{array}{l}\text { Degree of } \\
\text { freedom }\end{array}$} & \multirow[t]{2}{*}{$p$} & \multirow[t]{2}{*}{$\operatorname{Exp}(B)$} & \multicolumn{2}{|c|}{ Hazard ratio } \\
\hline & & & & & & & Lower & Upper \\
\hline \multicolumn{9}{|l|}{ Socio-demographic } \\
\hline Age at start of sick leave & & & 15.66 & 3 & 0.001 & & & \\
\hline $20-29$ & & & & & & 1.00 & Reference & \\
\hline $30-39$ & -1.05 & 0.31 & 11.44 & 1 & 0.001 & 0.35 & 0.19 & 0.64 \\
\hline $40-49$ & -1.19 & 0.37 & 10.61 & 1 & 0.001 & 0.30 & 0.15 & 0.62 \\
\hline$\geqq 50$ & -0.28 & 0.50 & 0.32 & 1 & 0.57 & 0.75 & 0.28 & 2.00 \\
\hline \multicolumn{9}{|l|}{ Sex ${ }^{a}$} \\
\hline Male & & & & & & 1.00 & Reference & \\
\hline Female & -0.05 & 0.24 & 0.05 & 1 & 0.83 & 0.95 & 0.60 & 1.51 \\
\hline \multicolumn{9}{|l|}{ Clinical } \\
\hline Number of previous sick leave ${ }^{b}$ & & & 6.39 & 2 & 0.04 & & & \\
\hline 0 & & & & & & 1.00 & Reference & \\
\hline 1 & -0.24 & 0.25 & 0.91 & 1 & 0.34 & 0.79 & 0.48 & 1.29 \\
\hline $2 \leqq$ & -0.71 & 0.29 & 6.16 & 1 & 0.01 & 0.49 & 0.28 & 0.86 \\
\hline \multicolumn{9}{|l|}{ Work related } \\
\hline Employee rank ${ }^{b}$ & & & 20.12 & 3 & $<0.001$ & & & \\
\hline Manager & & & & & & 1.00 & Reference & \\
\hline Senior staff & 0.44 & 0.28 & 2.49 & 1 & 0.12 & 1.55 & 0.90 & 2.66 \\
\hline Normal staff & -0.44 & 0.35 & 1.53 & 1 & 0.22 & 0.65 & 0.32 & 1.29 \\
\hline Assistant staff & -2.12 & 0.79 & 7.23 & 1 & 0.01 & 0.12 & 0.03 & 0.56 \\
\hline
\end{tabular}

be that a selection bias known as the "healthy workers effect" might have occurred [21]. This takes place due to employees with mental disorders being more likely to leave the company. As a result, elder workers are likely to be mentally healthier than those of younger age.

\section{Clinical factors}

The results in this study imply that the number of previous episodes of sick leave have a significant influence on sick leave duration. In preceding research, frequency of sick leave was related to work disability and job termination [22]. It is difficult for the persons with multiple sick leave to return to work, because of their work disability. It may follow longer sick leave and job termination in the end under the Japanese work system.

\section{Work-related factors}

The results showed that employee rank was a predictor of duration of sick leave in Japan. One possible explanation of this result could be that the characteristics of the job roles in that company might have affected the results.

The absence duration of assistant staff was significantly longer than that of managers in this study. A possible reason for this could be that assistant staff might feel less pressure to return to work early because of the relatively lighter duties in their job. Therefore, it might be more difficult for them to be assigned a lighter workload on their return to work, as they already had light-duty jobs when they took sick leave, and this could therefore slow their return to work. Another reason for this result might be related to vulnerability of the workers. Considering that assistant staff suffer mental disorders under relatively light-duty, they are possibly more vulnerable to workplace stressors, and hence they needed to take more days off to recover compared with other employee ranks.

Senior staff showed the shortest duration of sick leave. As previously mentioned, senior staff are expected to perform at management-level as leaders of their team. In addition, they are also expected to work as non-executive employees. In Japan, this double role is known as "playing manager". Many senior staff members have to perform this multiple role, and when they take sick leave, the impact of their absence on the workplace could be much more extensive than that of others. Thus, it could be possible that such work-related pressure might urge senior staff to return to work earlier.

This study has some limitations. Firstly, the participants in this study were derived from a single company and the sample size was relatively small. In order to be representative of all workers in Japan, future studies including 
a larger number of participants from a greater range of companies would be worthwhile. In addition, variables included in the analysis were mainly socio-demographic and clinical factors. There is a possibility that other factors such as severity of symptoms, work environment, and interpersonal relationships with colleagues could also be predictive factors of returning to work following sick leave [19, 23-26]. Therefore, future studies need to examine these factors. These limitations should be taken into consideration when interpreting the results of this study.

\section{Conclusion}

Diagnosis, number of previous sick leave episodes, and employee rank are predictors of duration of sick leave due to mental disorders. This is the first study on predicting factors of the duration of sick leave due to mental disorders in Japan. When we consider more effective interventions to prevent protracted sick leave, those factors found by this study are quite critical. Future research is warranted on a larger scale of workers across a greater number of companies in Japan.

\section{Abbreviations}

DSM-IV: the Diagnostic and Statistical Manual of Mental Disorders, Fourth Edition; JPY: Japanese Yen; USD: United States Dollars; SD: standard deviation; SE: standard error.

\section{Authors' contributions}

SS and MS conceived and designed the study. SS and MS drafted the study protocol. MS organised and supervised study implementation, and SS drafted the manuscript. HT, JS and MM refined the study protocol and study implementation. AN provided methodological and statistical expertise. SS, MS and AN conducted the statistical analyses. SS, MS, AN, and MM interpreted the results. MS drafted the grant proposal and was responsible for study implementation. MS was responsible for study management. MA, CI, ST, and YM collected data. All authors critically reviewed the manuscript for content and approved the final version. SS, MS and AN had full access to all of the data throughout the study and take responsibility for the integrity of the data and the accuracy of the analysis. All authors read and approved the final manuscript.

\section{Author details}

${ }^{1}$ Center for Counseling and Disability Services, Tohoku University, Sendai, Japan. ${ }^{2}$ Department of Neuropsychiatry, Keio University School of Medicine, Shinanomachi 35, Shinjuku-ku, Tokyo 160-8582, Japan. ${ }^{3}$ Center for Stress Research, Keio University, Tokyo, Japan.

\section{Acknowledgements}

Not applicable.

\section{Competing interests}

The authors, MS and JS have received research fund from the company and the salary of the authors, AN, MA, ST, CI, YM, and JS is partly based on the research fund from the company.

\section{Availability of data and materials}

The datasets used in the current study are not publicly available due to the privacy policy of the company in related to this study. However, additional analyses, if reasonable, are available from the corresponding author under the adherence of this policy.

\section{Consent to publish}

Not applicable.

\section{Ethics approval and consent to participate}

We utilized secondary anonymous data that had been already obtained during the usual process of return to work in the company. Therefore, we conducted this study with opt out consent method. This study was approved by the Clinical Research Ethics Committee at Keio University School of Medicine (reference: 2013-485).

\section{Funding}

This research is conducted by the fund from the company. The company was not involved in any process such as, developing study design and protocol, the data collection, analysis, interpretation of data and writing the manuscript.

\section{Publisher's Note}

Springer Nature remains neutral with regard to jurisdictional claims in published maps and institutional affiliations.

Received: 1 November 2018 Accepted: 23 March 2019

Published online: 30 March 2019

\section{References}

1. WHO International Consortium in Psychiatric Epidemiology. Crossnational comparisons of the prevalences and correlates of mental disorders. Bull World Health Organ. 2000;78:413-26.

2. Directorate for Employment, Labour and Social Affairs, Organisation for Economic Co-operation and Development (OECD). Sickness, disability and work: keeping on track in the economic downturn. 2009. http:// www.oecd.org/dataoecd/42/15/42699911.pdf. Accessed 26 Nov 2016.

3. Smit F, Cuijpers P, Oostenbrink J, Batelaan N, de Graaf R, Beekman A. Costs of nine common mental disorders: implications for curative and preventive psychiatry. J Ment Health Policy Econ. 2006;9:193-200.

4. Sado M, Inagaki A, Koreki A, Knapp M, Kissane LA, Mimura M, Yoshimura K. The cost of schizophrenia in Japan. Neuropsychiatr Dis Treat. 2013;9:787-98.

5. Sado M, Inagaki A, Yoshimura K, Koreki A, Fujisawa D. The estimate of the societal cost caused by mental illness. Tokyo: Ministry of Health Labour and Welfare of Japan; 2011 (in Japanese)

6. Stansfeld SA, Fuhrer R, Head J. Impact of common mental disorders on sickness absence in an occupational cohort study. Occup Environ Med. 2011;68:408-13.

7. Stansfeld SA, Fuhrer R, Shipley MJ, Marnot MG. Work characteristics predict psychiatric disorder. Occup Environ Med. 1999;56:302-7.

8. Stansfeld S, Feeney A, Head J, Canner R, North F, Marmot M. Sickness absence for psychiatric illness: the Whitehall II study. Soc Sci Med. 1995;40:189-97.

9. Kitagawa N, Koga Y, Watanabe N, Kato C, Kawai T, Koyama T. Practice and efficacy of reinstatement support program for patients with depression. Jpn J Psychosom Med. 2009;49:123-31 (in Japanese).

10. World Health Organization (WHO). Mental health policies and programs in the workplace: WHO mental health policy and service guidance package-module 13. 2005. https://www.who.int/mental_health/polic y/services/13_policies\%20programs\%20in\%20workplace_WEB_07. pdf?ua=1. Accessed 26 Nov 2016

11. Vaez M, Rylander G, Nygren A, Asberg M, Alexanderson K. Sickness absence and disability pension in a cohort of employees initially on longterm sick leave due to psychiatric disorders in Sweden. Soc Psychiatry Psychiatr Epidemiol. 2007:42:381-8.

12. Cornelius LR, van der Klink JJ, Groothoff JW, Brouwer S. Prognostic factors of long term disability due to mental disorders: a systematic review. J Occup Rehabil. 2011;21:259-74.

13. Blank L, Peters J, Pickvance S, Wilford J, Macdonald E. A systematic review of the factors which predict return to work for people suffering episodes of poor mental health. J Occup Rehabil. 2008;18:27-34. 
14. Hensing G, Spak F. Psychiatric disorders as a factor in sick-leave due to other diagnoses: a general population-based study. Br J Psychiatry. 1998;172:250-6.

15. Goetzel RZ, Hawkins K, Ozminkowski RJ, Wags S. The health and produc tivity cost burden of the "top 10" physical and mental health conditions affecting six large US employers in 1999. J Occup Environ Med. 2003;45:5-14.

16. Gatchel RJ, Adams L, Polatin PB, Kishino ND. Secondary loss and painassociated disability: theoretical overview and treatment implications. J Occup Rehabil. 2002;12:99-110.

17. Briand C, Durand MJ, St Arnaud L, Corbiere M. Work and mental health: learning from return-to-work rehabilitation programs designed for workers with musculoskeletal disorder. Int J Law Psychiatry. 2007;30:444-57.

18. Sado M, Shirahase J, Yoshimura K, Miura Y, Yamamoto K, Tabuchi H, Kato M, Mimura M. Predictors of repeated sick leave in the workplace because of mental disorders. Neuropsychiatr Dis Treat. 2014;10:193-200.

19. Murphy LR. Stress management in work settings: a critical review of the health effects. Am J Health Promot. 1996;11:112-35.

20. Statistics Bureau, Ministry of Internal Affairs and Communications of Japan. The general survey of employment structure in Japan. 2013. http://www.stat.go.jp/data/shugyou/2012/pdf/kgaiyou.pdf. Accessed 26 Nov 2016 (in Japanese)
21. Koopmans PC, Roelen CA, Groothoff JW. Frequent and long-term absence as a risk factor for work disability and job termination among employees in the private sector. Occup Environ Med. 2008;181:208-13.

22. Koopmans PC, Roelen CAM, Groothoff JWG. Frequent and long-term absence as a risk factor for work disability and job termination among employees in the private sector. Occup Environ Med. 2008;65:494-9.

23. Judd LL, Akiskal HS, Zeller PJ, Paulus M, Leon AC, Master JD, Endicott J, Coryell W, Kunovac JL, Mueller TI, Rice JP, Keller MB. Psychosocial disability during long-term course of unipolar major depression disorder. Arch Gen Psychiatry. 2000;57:375-80.

24. Soderman E, Lisspers J, Sundin O. Depressive as a predictor of return to work in patients with coronary artery disease. Soc Sci Med. 2003:56:193-202.

25. Janssen N, van den Heuvel WP, Beurskens AJ, Nijhuis FJ, Schroer CA, van Eijk JT. The demand-control-support model as a predictor of return to work. Int J Rehabil Res. 2003:26:1-9.

26. Paoli P, Merllie D. Third European Survey on Working Conditions 2000. Luxembourg: Office for Official Publications of the European Communities. 2000. http://www.eurofound.europa.eu/sites/default/files/ef_files/ pubdocs/2001/21/en/1/ef0121en.pdf. Accessed 26 Nov 2016.
Ready to submit your research? Choose BMC and benefit from:

- fast, convenient online submission

- thorough peer review by experienced researchers in your field

- rapid publication on acceptance

- support for research data, including large and complex data types

- gold Open Access which fosters wider collaboration and increased citations

- maximum visibility for your research: over 100M website views per year

At BMC, research is always in progress.

Learn more biomedcentral.com/submissions 